\section{Liver failure Due to Diffuse Neonatal Hemangiomatosis}

Keywords: Hemangioma; Diffuse hemangiomatosis; Liver failure Neonatal; Propranolol

\begin{abstract}
The term Diffuse Neonatal Hemangiomatosis (DNH) has been used to describe multifocal vascular lesions affecting the skin and organs with the liver being the organ most frequently involved. Although spontaneous regression is the rule, complications such as a high cardiac output caused by portovenous or arteriovenous shunts can occur. Liver lesions can be potentially lethal due to severe complications such as fulminant hepatic failure. Mortality varies between $60-80 \%$ in the first months of life without treatment. Propranolol has been reported as an effective and well-tolerated treatment for cutaneous hemangiomas and more recently in hepatic hemangiomas.

We report the case of an infant with a diffuse neonata hemangiomatosis with hepatic hemangioma, which caused liver failure and successfully responded to treatment with propranolol.
\end{abstract}

\section{Introduction}

Congenital vascular lesions are relatively common disorders that have multiple forms of presentation, some with a tendency to resolve spontaneously and others associated with hemangiomatous lesions of internal organs. Depending on their location they can cause heart failure, anemia, hepatic failure, ocular and brain disorders, and even death [1].

Hemangiomas are benign vascular tumors composed of proliferating endothelium. They typically occur during the first two months of life in $90 \%$ of cases. Benign neonatal hemangiomatosis $(\mathrm{BNH})$ is diagnosed when five or more skin lesions are present. When vascular lesions affect the skin and viscera the disease is known as Diffuse Neonatal Hemangiomatosis (DNH), which is a serious systemic disorder that is present in 1 to $2.6 \%$ of infants born at term. Many publications emphasize the severity of $\mathrm{DNH}$, citing a mortality of $60-80 \%$ [2].

Lister first described DNH in 1938 [3], and in 2008 Leauté reported regression of hemangiomas in children treated with propranolol [4]. Since then, several series have confirmed the benefit of propranolol in the involution of infantile cutaneous hemangiomas and for the treatment of isolated hemangiomas in other locations $[5,6]$.

\section{Case Report}

The patient is a 45-day-old male infant with respiratory distress, tachypnea, intercostal retractions and nasal flaring. In the last $24 \mathrm{hrs}$, he refused to eat. On physical examination, he had a heart rate of 160 beats/minute and an oxygen saturation of $89 \%$. Multiple papulelike purple lesions compatible with hemangiomas were noted. These were $1-3 \mathrm{~mm}$ in diameter and located on his thorax, abdomen and extremities, in addition to a $1 \mathrm{~mm}$ lesion on his scalp. His skin also presented generalized jaundice. In the chest, a holosystolic grade III/VI murmur was heard. The abdomen was found distended with hepatomegaly $4 \mathrm{~cm}$ below the right costal border at the midclavicular line and with grade II splenomegaly.

\section{Journal of}

Clinical \& Medical Case Reports

Cura-Esquivel I*, Montes-Tapia F, Rodriguez-Tamez A, Sanchez-Cortes G and González JE

Department of Pediatrics, Autonomous University of Nuevo Leon, Mexico

Address for Correspondence:

Cura-Esquivel I, Department of Pediatrics, Autonomous University of Nuevo Leon, Hospital Universitario, Av. Madero y Gonzalitos s/n, Monterrey, Nuevo León, CP64360, México, Tel: +52 8183485 421; E-mail: idalia.curaesq@ uanl.edu.mx (or) idaliaaracely2008@hotmail.com

Submission: 26 October, 2018

Accepted: 28 January, 2019

Published: 31 January, 2019

Copyright: ๑ 2019 Cura-Esquivel I, et al. This is an open access article distributed under the Creative Commons Attribution License, which permits unrestricted use, distribution, and reproduction in any medium, provided the original work is properly cited.

Initial laboratory tests revealed hemoglobin of $10.9 \mathrm{~g} / \mathrm{L}$, a hematocrit of $30.9 \%$, leukocytes $9,260 / \mathrm{mm}^{3}$ and platelets $243,000 /$ $\mathrm{mm}^{3}$. Liver function tests showed total bilirubin $10.9 \mathrm{mg} / \mathrm{dL}$, direct bilirubin $1.9 \mathrm{mg} / \mathrm{dL}$, indirect bilirubin $9 \mathrm{mg} / \mathrm{dL}$, albumin $3 \mathrm{~g} / \mathrm{dL}$, AST $160 \mathrm{U} / \mathrm{L}$, ALT $178 \mathrm{U} / \mathrm{L}, \mathrm{LDH} 585 \mathrm{U} / \mathrm{L}$, alkaline phosphatase $246 \mathrm{U} / \mathrm{L}$,

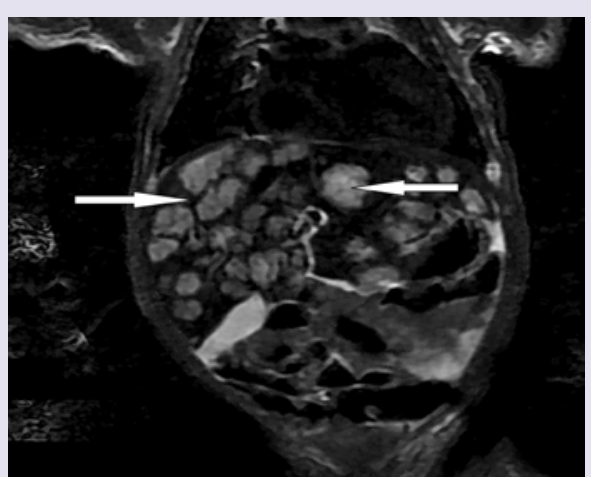

Figure 1: MRI delineates multiple discrete homogeneous lesions, $10-30 \mathrm{~mm}$ in diameter with very little liver parenchymal between them.

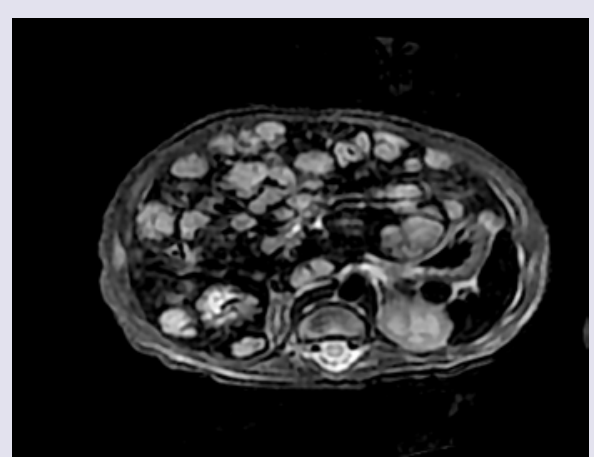

Figure 2: An axial T2 magnetic resonance image with fat saturation demonstrates multiple hyperintense lesions with near total hepatic parenchymal replacement. 


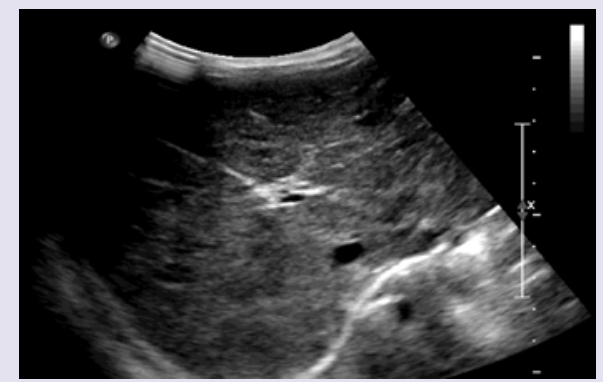

Figure 3: Ultrasound scans images twenty-four months later: grayscale injury happens now unnoticed.

gamma-glutamyl transpeptidase $178 \mathrm{U} / \mathrm{ml}$, creatinine $0.4 \mathrm{mg} / \mathrm{dL}$, ammonium $80 \mathrm{mg} / \mathrm{dL}$, and clotting times TP $15.8 \mathrm{sec}$, TTP $43.4 \mathrm{sec}$ and INR 1.3. A thyroid profile was normal. The chest $\mathrm{x}$-ray showed cardiomegaly with a cardiothoracic index of 0.58 and increased pulmonary vasculature. An echocardiogram showed a high cardiac output with heart failure, elevated pulmonary artery pressure and a patent ductus arteriosus. Abdominal ultrasound showed moderate hepatomegaly $(7.5 \mathrm{~cm})$ with a heterogeneous echotexture and countless hypoechoic lesions involving the entire liver parenchyma. A contrasted magnetic resonance image of the abdomen demonstrated an enlarged liver. The main hepatic artery, hepatic veins and inferior vena cava were dilated. Multiple hypointense focal lesions on T1 and hyperintense on T2, 10-30 mm in diameter with very little liver parenchymal between them were seen. MRI findings were consistent with diffuse hepatic hemangioma (Figure 1 and 2). Extension studies of the brain and lung showed no lesions.

Treatment for heart failure with digoxin and furosemide was started. Also, prednisolone $2 \mathrm{mg} / \mathrm{kg} /$ day and propranolol at an initial dose of $1 \mathrm{mg} / \mathrm{kg} /$ day and gradually increased to a dose of $3 \mathrm{mg} / \mathrm{kg} /$ day were administered for DNH. The patient remained hospitalized in the Pediatric Intensive Care Unit for 3 weeks. His cardiovascular status stabilized after 14 days of treatment. Liver function also gradually normalized. At 3 weeks of treatment jaundice had disappeared and liver function tests were normal (Albumin $3.9 \mathrm{mg} / \mathrm{dL}$, TP $12.2 \mathrm{sec}$ and TTP $18 \mathrm{sec}$ ). Treatment with prednisolone was stopped after four weeks and propranolol was continued for 10 months. At 12 months of age, the skin lesions had disappeared. A follow-up ultrasound showed normal liver size with a reduction of hypoechoic lesions (less than $2 \mathrm{~mm}$ ). At 24 months of follow-up the patient had no evidence of heart failure and normal liver function. The liver hemangiomas were almost imperceptible on abdomen ultrasound and MRI (Figure 3).

\section{Discussion}

Hemangiomas are the most common benign tumors in childhood. They were initially considered neoplastic lesions that originated in the vascular endothelium; they are now known to be benign endothelial cell neoplasm's characterized by rapid growth followed by involution in the early years of life.

Infantile Hepatic Hemangiomas ( $\mathrm{IHH})$, in particular of the diffuse subtype, can be associated, in severe cases, with hepatic and cardiac insufficiency. The early recognition of this entity is essential to start treatment and reduce the risk of long-term sequela and even death.
In 1970 Holden and Alexander suggested diagnosing DNH based on 3 criteria that included 1) presentation during the neonatal period 2) no evidence of malignancy, and 3) involvement of various organs or systems [7]. In DNH, skin hemangiomas are located almost anywhere in the body including the mucosa, and their size varies from a few millimeters to $5 \mathrm{~cm}$. Visceral hemangiomas can compromise various internal organs, such as the liver, heart, lung, gastrointestinal tract, retina, spleen, pancreas, bladder, kidney, bladder, meninges, choroid, etc. [8].

The signs of systemic compromise may be subtle, and include failure to thrive (secondary to underlying thyroid or cardiac dysfunction) and feeding difficulties. The presence of hepatomegaly on clinical examination should expedite radiological investigation.

Liver hemangiomas, especially those that are multiple and large, are associated with high mortality. One complication is high-output congestive heart failure (51\%) because these lesions simulate the hemodynamic alterations of a left-right shunt.

The clinical presentation can vary and include liver dysfunction $[9,10]$, hyperammonemia, hepatosplenomegaly $(5.3 \%)$, renal failure (10.6\%) and hypothyroidism (5.3\%). Although the spontaneous regression is the rule with the liver hemangiomas, complications such as a high cardiac output caused by portovenous or arteriovenous shunts can occu like in our patient.

Liver failure is a rare complication with high mortality and is suspected with elevated transaminases, coagulopathy and encephalopathy. A mortality rate of $60-80 \%$ without treatment has been reported $[4,5,11,12]$.

However, with proper treatment mortality is reduced to $27 \%$.

Treatment is aimed at preventing complications. Several therapeutic options have been described including observation, use of interferon alfa- $2 \mathrm{~b}$, vincristine, vinblastine, cyclophosphamide, steroids, propranolol or non-pharmacological treatments, such as radiation therapy, embolization or surgery [13].

Corticosteroids limit proliferation of blood vessels and induce early regression. They are first-line treatment for severe and complicated infantile hemangiomas. The response rate varies from $30-50 \%[14,15]$.

The efficacy of propranolol in the treatment of hemangiomas has been described since 2008. Its mechanism of action remains unclear; however, some suggested mechanisms are a cytotoxic effect on endothelial cells, inhibition of matrix metalloproteinase, and modulation of stem cell differentiation $[16,17]$.

We report the case of an infant with $\mathrm{DNH}$ with liver failure secondary to liver hemangiomas. Based on reports that propranolol has been effective in the treatment of hemangiomas in children, we offered this therapy to our patient who showed dramatic improvement of liver failure, demonstrated by the recovery of liver metabolism and synthesis.

\section{Conclusion}

Diffuse neonatal hemangiomatosis is a rare and potentially fatal disease. Due to its rapid development, early intervention is necessary to prevent progression or produce regression. 
Citation: Cura-Esquivel I, Montes-Tapia F, Rodriguez-Tamez A, Sanchez-Cortes G, González JE. Liver failure Due to Diffuse Neonatal Hemangiomatosis. J Clin Med Case Reports. 2019;6(1): 3.

In this case, liver failure secondary to DNH occurred, which resolved effectively with steroids and propranolol. The primary cause of liver failure was the hepatic hemangiomas. The administration of propranolol had a fast and consistent therapeutic effect allowing control of the complications caused by hemangiomas. It also shortened the natural history of the disease (proliferation phase) and contributed to its resolution with good tolerance.

\section{References}

1. Drolet BA, Esterly NB, Friden IJ (1999) Hemangiomas in children. N Engl J Med 341: 173-181.

2. Agarwal S, Sharma A, Maria A (2017) Diffuse neonatal hemangiomatosis presenting as congestive heart failure. Dermatol Pract Concept 7: 66-69.

3. Lister WA (1938) The natural history of strawberry naive. Lancet 1: 14291434.

4. Leaute-Labreze C, Dumas de la Roque E, Hubiche T, Boralevi F, Thambo JB (2008) Propranolol for severe hemangiomas of infancy. N Engl J Med 358: 2649-2651.

5. Bosemani T, Puttgen KB, Hulsman TA, Tekes A (2012) Multifocal infantile hepatic hemangiomas--imaging strategy and response to treatment after propranolol and steroids including review of the literature. Eur J Pediatr 171: 1023-1028.

6. Sans V, de la Roque ED, Berge J, Grenier N, Boralevi F, et al. (2009) Propranolol for severe infantile hemangiomas: follow-up report. Pediatrics 124: e423-e431.
7. Holden KR, Alexander F (1970) Diffuse neonatal hemangiomatosis Pediatrics 46: 411-421.

8. Golitz LE, Rudikoff J, O'Meara OP (1986) Diffuse neonatal hemangiomatosis Pediatr Dermatol 3: 145-152.

9. Kilcline C, Frieden IJ (2008) Infantile hemangiomas: how common are they? A systematic review of the medical literature. Pediatr Dermatol 25: 168-173.

10. Zenzen W, Perez-Atayde AR, Elisofon SA, Kim HB, Alomari Al (2009) Hepatic failure in a rapidly involuting congenital hemangioma of the liver: failure of embolotherapy. Pediatr Radiol 39: 1118-1123.

11. Sevinir B, Ozkan TB (2007) Infantile hepatic hemangioendothelioma: clinical presentation and treatment. Turk J Gastroenterol 18: 182-187.

12. Chen CC, Kong MS, Yang CP, Hung IJ (2003) Hepatic hemangioma in children: analysis of thirteen cases. Acta Paediatr Taiwan 44: 8-13.

13. Touloukian RJ (1970) Hepatic hemangioendothelioma during infancy: pathology, diagnosis and treatment with prednisone. Pediatrics 45: 71-76.

14. Dickie B, Dasgupta R, Nair R, Alonso MH, Ryckman FC, et al. (2009) Spectrum of hepatic hemangiomas: management and outcome. J Pediatr Surg 44: 125-133.

15. Gunturi N, Ramgopal S, Balagopal S, Scott JX (2013) Propranolol therapy for infantile hemangioma. Indian Pediatr 50: 307-313.

16. Mazereeuw-Hautier J, Hoeger PH, Benlahrech S, Ammour A, Broue P, et al. (2010) Efficacy of propranolol in hepatic infantile hemangiomas with diffuse neonatal hemangiomatosis. J Pediatr 157: 340-342.

17. Marsciani A, Pericoli R, Alaggio R, Brisigotti M, Vergine G (2010) Massive response of severe infantile hemangioma to propranolol. Pediatr Blood Cancer 54: 176. 